\title{
¿Guerra o comercio pacífico? La problemática interétnica del Chaco centro-occidental en el siglo XVIII *
}

\author{
Daniel J. Santamaría \\ y Jaime A. Peire
}

Universidad Nacional de Jujuy y Universidad

Nacional de Luján. Argentina

Generalmente se concibe al Chaco como un espacio vacio que tiene, en todo caso, interés para los antropólogos. Pero la evidencia documental, las crónicas y ciertas consideraciones lógicas nos permiten sostener la hipótesis de que ese enorme espacio habitado por pueblos que rechazaron la colonización europea, fue de modo permanente un escenario de intensas transacciones comerciales y sus concomitantes préstamos culturales. En este artículo se examinan aquellos hechos que ofrecen alternativas a la guerra de fronteras: en particular, el reclutamiento laboral de los aborígenes en las haciendas españolas y las propuestas que los mercaderes de fines del XVIII hicieron a las autoridades con vistas a confirmar a la región como zona comercial y acaso productiva, poniendo a la guerra como un ejercicio inútil.

\section{El Chaco Occidental como reserva de fuerza de trabajo para el espacio hispanocolonial tucumano}

Al revés de lo ocurrido en otros sistemas misionales de Sudamérica, donde los jesuitas lograron un cierto aislamiento seguramente intencional, orientado al éxito de economías que garantizaran la autosuficiencia, con relaciones comerciales de larga distancia, que incluían el contrabando de bienes por los circuitos fluviales del centro del continente, ${ }^{1}$ en el Chaco centro-occidental fue del todo imposible repetir una experiencia semejante.

* Una versión preliminar de este trabajo fue presentada a las XI Jornadas de Historia Económica organizadas por la Asociación Argentina de Historia Económica, el Consejo Latinoamericano de Ciencias Sociales (CLACSO) y la Universidad Nacional de Luján entre el 27 y el 29 de junio de 1990.

1 Santamaria, D. J.: La economía de las misiones de Moxos y Chiquitos (1675-1808). "Ibero Amerikanisches Archiv", Berlin, 1987, neue Folge, 13 (2), págs. 255-295. 
Una de las razones fue que el poder militar convirtió aquí a las misiones en parte integrante de sus propias estrategias las cuales perseguían, globalmente, el control de poblaciones para ofrecer mano de obra barata y segura a los productores agropecuarios del Tucumán. La esclavización se fundamentaba, como era habitual, en una descripción del indio que enfatizaba sus rasgos de salvajismo. Una crónica citada por Arenales ${ }^{2}$ los define

"belicosos y grandes conquistadores de las naciones comarcanas a sus tierras y muy temidos porque los matan en las guerras que de ordinario les hacen por quitarles los hijos y mujeres que cautivan muchos y los venden y los rescatan los vecinos de Asunción".

También Gerónimo de Matorras, gobernador de Salta y uno de los tantos jefes expedicionarios al Chaco, denuncia que por mucho tiempo

"han sido tratadas estas naciones con el rigor de la guerra a causa de sus invasiones y estragos en las fronteras y en todas las expediciones se sacaban cuantos podían cogerse y repartían entre los individuos que asistían a las entradas y estos los vendían al que mejor se los pagaba y otros se daban en calidad de encomienda". 3

Si damos crédito al texto de Matorras, se practicaban en la región varios métodos de apropiación de mano de obra indígena, una función supletoria que acompañaba, en medio de grandes dificultades, a las otras dos:

a) compra o rescate de prisioneros de guerra capturados por los guaykurúes en las guerras interétnicas que desde el siglo XVII sacuden la enorme extensión del Chaco;

b) reparto de prisioneros de guerra entre los soldados coloniales o los oficiales de las tropas expedicionarias, muchos de ellos labradores, comerciantes o mercaderes;

2 Arenales, José de: Noticias Históricas y Descriptivas sobre el gran país del Chaco y el río Bermejo. Buenos Aires (Colección De Angelis), 1833, págs. 91-92.

3 Matorras, Gerónimo: Diario Descriptivo de la expedición hecha a los países del Gran Chaco (1774). Archivo General de la Nación (en adelante AGN), Interior, 5-10, f. 27v. 
c) venta de indios esclavizados por las autoridades militares o capitulares según la demanda permanente o estacional del mercado de trabajo constituido por obrajeros, almonas, viñas, rudimentarios trapiches de azúcar o aún la propia demanda de trabajo doméstico en fincas urbanas.

Este fenómeno pesó sobre los fortines y misiones del Occidente del Chaco, controlados por las autoridades de Tucumán, Salta y Jujuy y en las misiones del Bermejo inferior controladas por Corrientes y Asunción del Paraguay.

En los primeros tiempos de la colonia, la maloca había sido el método preferido: se sobornaba a los etnogrupos más belicosos para inducirlos a hostilizar y eventualmente esclavizar a sus enemigos tradicionales. Una vez sometidos, se les proponía traerlos a las haciendas y obrajes de españoles como mano de obra adicional. También, por supuesto, se apelaba a la agresión directa aunque no con el carácter sistemático que tomaría en el XVIII. Con todo, la participación del chaqueño en el trabajo agropecuario de los valles altos no parece muy significativa y sólo existen casos de mujeres indias repartidas para el servicio doméstico. ${ }^{4}$ De modo que las conclusiones del texto de Matorras valen plenamente sólo para las tierras bajas de Salta y Jujuy donde a fines de siglo se iniciaría una rústica industria azucarera. ${ }^{5}$

Sólo cuando las relaciones hispano-indígenas se hagan más frecuentes, esa fuerza de trabajo será utilizada en las misiones más como soldados que como productores, sobre todo porque los grupos sedentarizados reconocían sólo una rudimentaria tradición agrícola. La documentación los menciona a veces con los nombres habituales de indios de mita o indios feudales, reservados a todos aquellos sometidos al régimen de servicio personal.

La actitud de las autoridades no cambiará hasta fines de la colonia; todavía en 1803 el gobernador-intendente de Salta informa

4 Garavaglia, Juan Carlos: La guerra en el Tucumán colonial: sociedad y economía en un área de frontera, 1660-1760. "HISLA", IV, Lima, 1984.

5 Lagos, Marcelo: Conformación del mercado de trabajo en torno de los ingenios azucareros jujeños. Tesis de Licenciatura inédita, Universidad de Jujuy, 1990. 
que una treintena de indios apresados en los campos orientales, acusados otra vez de "invasión" y "saqueo", se habían fugado. Las mujeres que no lo hicieron fueron repartidas "entre señoras principales para que las instruyeran en el cristianismo". ${ }^{6}$

En contra de los objetivos del proyecto jesuita, la guerra nunca desapareció como fuente de trabajo gratuito. Otro caso de la misma época: cien invasores tobas atrapados en las fronteras sudoccidentales fueron destinados a los cañaverales del valle de San Francisco. Se blandió el argumento de que faltaban peones y que su trabajo podía

"compensar su manutención, la de su chusma y el costo de su cepo en que aseguran a los varones de noche". ${ }^{7}$

Ubicados más al norte, los wichíes o matacos fueron los primeros habitantes autóctonos enrolados como mano de obra barata y bastante estable en las haciendas salteñas. Arias los conceptuaba dóciles, sencillos, valientes, aplicados al trabajo. Familias enteras se emplearon en las obras públicas de la ciudad o en el servicio militar de los presidios de frontera, y sus mujeres casi siempre eran conducidas a casas particulares como servidoras domésticas. ${ }^{8}$ Este ir y venir de wichíes a la ciudad pronto los indujo a usarla como una estrategia de supervivencia, integrándola como eslabón en sus tradicionales cadenas de intercambio. En 1790 el cacique Clemente Anaya, invocando la probada fidelidad de su pueblo al amo colonial, pidió permiso para que jóvenes de su tribu entrasen a Salta a vender los productos de su región, en la confluencia del río Dorado y el Seco; podrían ofrecer cera, miel, redes de pesca, chaguar, plumas y pieles de diversos animales. El cacique esperaba que estas ventas, sumadas a los jornales obtenidos en el trabajo urbano, les permitie-

6 AGN, Hacienda, IX, 34-4-3.

7 Ídem.

8 Arias, Francisco Gabino: Diario y descripción de la expedición reduccional del año 1780 y 1781 al Gran Chaco y Segunda parte del Diario General que concluye con una noción y descripción geográfica de toda la provincia del Gran Chaco Gualamba, sus cualidades y variedad de innumerables bárbaras naciones que la habitan, 1780-1781. AGN, Guerra y Marina, 4-6, f. 16. 
ran acceder a útiles e instrumentos de manufactura europea, especialmente hachas y cuchillos.

También varios contingentes tobas fueron incorporados más adelante, a medida que fracciones relativamente marginales de ese pueblo vislumbraban algunos de los pocos beneficios que podían obtener del trato con los españoles, bien que muchos de ellos fueran llevados como virtuales prisioneros. En todos los casos, el argumento central para sujetar a estos pueblos era la falta de otros brazos:

"la escasez de gente de conchabo para la labranza en dicha provincia de Salta ha obligado a sus moradores a solicitar a los infieles para el conchabo de todo trabajo de a pie y de a caballo así en el campo como en la propia ciudad porque están ya instruidos en él, de modo que los más de aquellos vecinos se proveen de estos brazos por la necesidad y falta de otros". ${ }^{9}$

Esta carencia, real o supuesta, se soluciona con la guerra punitiva; en períodos de paz, por el contrario, pueden ejercitarse prudentes medios de persuasión ya probados en otras regiones del continente. Es aquí donde mejor se ve el fracaso de las reducciones evangelizadoras. En esos períodos de calma, los hacendados no tienen más remedio que solicitar de los jefes militares un número suficiente de esclavos indígenas; por ejemplo, cuando Mateo de Saravia y Jáuregui quiere cultivar su estancia de La Vieja, en el Río del Valle, le pide al gobernador salteño que ordene al comandante del fuerte local auxiliarle con quince o veinte matacos bajo "las calidades acostumbradas", es decir, salario, tributo y disciplinamiento. ${ }^{10}$

Pero no era raro que el reclutamiento siguiera vías más expeditivas, así los hacendados podían prescindir de las autoridades para conseguir por ellos mismos $-\mathrm{y}$ generalmente por medios violentos- la mano de obra necesaria. El mismo Saravia, actuando ahora como abogado de la Real Audiencia de La Plata y como regidor del Cabildo de Salta, denuncia en dos oportunidades que unos soldados se llevaron a los cañaverales de los Cornejo varios indios

9 AGN, Guerra y Marina, 38-12. Mateo de Saravia y Jáuregui, 17 de enero de 1806. 10 Ídem. 
matacos de su estancia, amarrados y atados a la cincha. Los indios se habían resistido porque conocían por experiencia el mal trato a que los sometía esa familia azucarera. "

Como los wichíes despreciaban la cañadulce silvestre (la "flecha del Diablo", como la llamaban) es probable que debieran compensar su magro ingreso con consumos espontáneos de carne como se hacía en las haciendas, ${ }^{12}$ actitud que los hacendados despojados describían - naturalmente - como un robo.

Por regla general, los indios sometidos a reparto permanecían entre cuatro y doce meses en las haciendas. Allí el doctrinero los visitaba para evangelizarlos y convencerlos de las ventajas de la vida sedentaria. A veces la persuasión se transformaba en castigos físicos, como los que le valieron al cura Juan José Ortiz un juicio criminal en $1808 .^{13}$

Si el número de indios repartidos era más o menos permanente durante el año, los tiempos de cosecha requerían contingentes adicionales; estos grupos eran empleados tres meses por año y luego volvían a sus tierras para seguir sustentándose al modo tradicional. ${ }^{14}$ Por supuesto que si al término de ese período de cosecha la demanda de brazos continuaba por algún motivo especial, trabajo en las iglesias o en las casas de particulares o en obras públicas capitulares, una parte variable de ese contingente adicional se quedaba por tiempo indefinido. ${ }^{15}$

La entrega de indios en encomienda, como vimos en la denuncia de Matorras, forma parte del reparto habitual y no se trata, en realidad, de una forma distinta de adquisición o control de trabajadores aborígenes. Pero posiblemente el nombre de indios feudales derive del hecho de que también su cooptación en el seno de las sociedades tribales se efectúa, las más de las veces, mediante una

11 Ibídem. Denuncias del 10 de septiembre de 1804 y 17 de enero de 1806.

12 Arias, F. G.: Diario y descripción..., f. 17v.

13 AGN, Criminales, 55-4. Declaración del hacendado Martín de Otero en el juicio contra Ortiz, 23 de marzo de 1808.

14 AGN, Interior, 60-1. José Suárez Valle al alcalde ordinario Tomás de Arrigunaga, 2 de noviembre de 1807.

15 AGN, Justicia, IX, 31-7-6. 
negociación directa con los caciques ya que no había encomiendas de españoles en el interior del Chaco. Un informe de 1786 recuerda los indios feudales que le había prometido a un regidor tucumano el cacique de Tolombón y Colalao. Es seguro que estos feudales no eran prisioneros de guerra sino miembros de la parcialidad del jefe otorgante. Es imposible determinar aquí si la decisión del líder étnico se vincula con un arreglo intraétnico sobre la prestación del trabajo estacional o si se trataba de una simple imposición autoritaria, basada en el poder político del cacique. ${ }^{16}$

Otro tema conexo con la mano de obra indígena es la remuneración pagada a los trabajadores indígenas. La documentación es en este aspecto bastante sumaria pero elocuente, así Juan José Ortiz paga a los indios aconchabados un salario mensual de 32 reales. ${ }^{17}$ Francisco Arias concede que no piden

"estos desdichados otro premio por su personal trabajo que la carne, que aprecian más que el oro y la plata, por la miseria y hambre con que siempre viven". ${ }^{18}$

Es probable que la cifra dineraria citada por Ortiz no fuera más que el valor estimado de la carne efectivamente entregada. Pero tampoco se les pagaba siempre con came sino con prendas, telas bastas, hilos, botones, cuchillos, tijeras y cosas por el estilo. La Visita de 1771 dice que

"repartió el señor gobernador a sus caciques principales vestidos de casaca a los mandones alcaldes y oficiales, solapas, sombreros, algunos calzones, camisas, frenos y espuelas y a todos los demás ropa de pañete y bayeta para vestirse, hilo, medallas, cintas, agujas, abalorios y otras baraterías... de suerte que quedaron todos gustosos". ${ }^{1}$

16 Archivo Histórico de Salta (en adelante AHS), Documentación de Gobierno, carpeta 13, exp. 6. Informe de Francisco Tejerina y Barreda, 1786. 1807.

17 AGN, Interior, 60-1. Juan José Ortiz al alcalde Arrigunaga, 3 de noviembre de

18 Arias, F. G.: Diario y descripción..., fol. 13v.

19 Archivo Histórico de la Provincia de Jujuy, fondos del Archivo de Ricardo Rojas (en adelante AHPJ-ARR), XL, leg. 2, año de 1771. Testimonio de auto de visita de reducciones mandado observar por el capítulo 14 del Nuevo Reglamento de Sisa y por el 9." contenido en éste (donde) se previene el repartimiento que se debe hacer a los indios. 
Una cuenta establece el valor de 178 pesos corrientes por lo entregado a 19 trabajadores en retribución de su mano de obra estacional en las haciendas. ${ }^{20}$ De todos modos, según denuncias contemporáneas, los aborígenes tenían la costumbre de abandonar el puesto en la hacienda, so pretexto de melear y cazar jabalíes, cuando la verdad era que se dedicaban a carnear los terneros de sus amos. ${ }^{21}$

Puede que esta actitud no sólo fuera contra los intereses de los hacendados españoles sino contra los de sus propios jefes étnicos; según el hacendado Otero, el cacique Feliciano se ha adueñado del ganado "que adquirieron los indios con el peso de los conchabos". Una vez faenado el animal y distribuida la carne entre los indios - se supone- el cacique vende el sebo y la grasa en las haciendas. ${ }^{22}$ Es evidente que, como en muchas regiones, los jefes étnicos se aprovechan de su estatuto político para obtener ventajas personales; las retribuciones especiales que reciben denuncian con elocuencia el rol que cumplen en el interior de sus etnogrupos como reclutadores primarios de trabajo aborigen, disipando toda sospecha sobre el presunto carácter "igualitario" de sus sociedades.

Wichíes y tobas son transportados todos los años, en contingentes considerables, a los ingenios de azúcar del valle de San Francisco para ser empleados en el cultivo de caña y en la zafra. ${ }^{23}$ Una vez el gobernador salteño Rafael de la Luz instruyó a los administradores de San Ignacio de los Tobas para que repartieran los indios en cuatro partes: unos quedarían en la reducción, otros marcharían a la hacienda de Ledesma, otros a la hacienda de Río Negro y los últimos a las de San Pedro y San Lucas. A veces esta distribución seguía criterios clasificatorios de la mano de obra, reputando mejor una que otra, o se atenían, sencillamente, al estado de turbulencia en las fronteras. Por ejemplo, la estancia de San Lorenzo empleaba wichíes y las autoridades coloniales sabían bien que no

20 AHS, Doc. de Gobierno, Carp. 13, Exp. 9. "Cuenta de lo que se ha pagado a la primera mita de indios del Chaco".

21 AGN, Interior, 60-1. Eduardo Salas a J. J.: Ortiz, 2 de noviembre de 1807.

22 AGN, Criminales, 55-4. Declaración del hacendado Martín de Otero.

23 AGN, Interior, 60-1. Informe de J. J. Ortiz. 
convenía mezclarlos con sus antiguos enemigos tobas. Si no se tenía a mano wichíes para la cosecha, debía subdividirse la cuarta porción. Esto ocurre durante el desyerbe, antes de la siembra, cuando "se sabe que no vienen matacos". Entonces se toman diez tobas de Río Negro y otros tantos de Ledesma. ${ }^{24}$

No hay duda de que los fortines de frontera cumplen también el rol de mercados naturales para los estancieros del Chaco; ellos demandan carne ${ }^{25}$ en cantidades poco despreciables si pensamos que las sumas pedidas por los comandantes, como los seis mil pesos que requirió Gregorio de Zegada, jefe de la frontera jujeña en 1784, iban directamente a las manos de los proveedores locales. ${ }^{26}$ Pero el volumen es demasiado alto para concluir que toda la carne comprada se consumía en los fortines; sus comandantes, a veces miembros de antiguas familias mercantiles, aprovechan las circunstancias para adquirir ganado barato y negociar luego en los mercados coloniales los remanentes de carne no consumida en los puestos de frontera.

De la paga de dinero o bienes se retiene a los indios la cuarta parte como tributo. Juan José Ortiz aduce que el gobierno desea retener la mitad (según el auto de la visita y un oficio que se le librara al propio Ortiz). Este considera justamente que semejante aumento de la exacción equivaldría a "tiranizarlos" porque de ese modo no les alcanzará "para mantener y vestir a sus hijos y a sus mujeres". El aumento del tributo en especies significa, sencillamente, que los comandantes retienen esos bienes para venderlos en el circuito mercantil. La tendencia a aumentar el tributo, es decir, a retener especies, sobre todo telas, se relacionaba por consiguiente con el mercado colonial y el alza de sus precios. De este modo el propio mercado regula de lejos el ingreso neto del trabajador chaqueño. La frontera se incorpora plenamente una vez más a la economía mercantilista.

Los tributos son retenidos por cada hacendado y éstos los giran anualmente a los administradores laicos o eclesiásticos de las

24 Ídem.

25 AGN, Hacienda, 68-1834.

26 AHS, Doc. de Gobierno, Carp. 11, exp. 3. Gregorio de Zegada a la Real Hacienda de Salta. 
reducciones. ${ }^{27}$ No sabemos si los tributos girados estaban compuestos siempre en especies; puede pensarse que los hacendados consiguen metálico con la venta de ganados en el circuito pero es difícil aceptar que lo entregaran como tributo (o parte de él) en la frontera. Entre las especies provistas por los propios indios casi ninguna tenía la entidad suficiente como para formar parte del tributo; es así que debían tomarlo de sus propios bienes, es decir, de los productos generados por el trabajo indígena. Y este producto esencial parece ser el ganado o las manufacturas ganaderas; un regidor tucumano dice precisamente que la mayor parte de los indios son vagabundos y para que paguen su tributo

"es necesario conchabarlos con alguno que pague por ellos" 28

es decir, algún ganadero que logre de ellos una producción capaz de asegurar a las autoridades el cobro del impuesto.

\section{Las políticas de "pacificación"}

Pero más allá de las remuneraciones, los negocios ganaderos o la percepción fiscal del tributo, la política de reclutamiento y disciplinamiento de la mano de obra indígena no podía perder el principal instrumento: la dominación militar o "pacificación" de la frontera. Incluso cuando algunas parcialidades ya cristianizadas pretenden habitar en tierras de españoles, éstos consideran el asunto con suma cautela. Veamos qué dice el protector de indios cuando el cacique Anaya hizo una propuesta semejante:

"el cacique principal de los matacos Anaya y su gente son cristianos y viviendo entre la gentilidad profesan (sin embargo) una vida gentilicia. El extraerlos con violencia para que guarden la ley santa como protestaron en el bautismo- sería aventurar su suerte futura, exasperar a sus parientes y amigos que le reconocen superior y exponer a un inminente riesgo la tranquilidad de nuestra frontera". ${ }^{29}$

27 AGN, Interior, 60-1. J. J. Ortiz a T. de Arrigunaga, 3 de noviembre de 1807.

28 AHS, Doc. de Gobierno, Carp. 13, exp. 6. Francisco de Tejerina y Barreda.

29 AGN, Interior, IX, 30-5-2. 
La opinión del protector de indios quizá no fuera apoyada por los sectores pastoriles de la región; si el permiso a otorgar a los wichíes para comerciar en Salta era después de todo una cuestión secundaria, no lo era reclutarlos para el trabajo agropecuario. Pero ese reclutamiento no debía ser siempre ejercido por violencia militar: si los fuertes cumplían la función clave de sedentarizar pueblos cazadores y recolectores, la fuga sólo podría evitarse, quizá para siempre, con la transformación de sus formas de vida. En este sentido las misiones debían cumplir su papel de manera satisfactoria. El problema era que los patrones de caza y recolección, que incluían el "robo" de ganado, entraban en contradicción con la expansión del frente pionero y pastoril al cual no alcanzaban las normas legales estatuidas para el resto del mundo colonial.

Aunque la preservación de la capacidad productiva de las comunidades indígenas, por medio de dominar tierras o recursos naturales imprescindibles, fue durante la colonia un procedimiento jurídico habitual para garantizar el pago del tributo, las cosas eran bastante distintas en el Chaco. El tributo no provenía aquí de lo producido en la economía indígena tradicional sino del plustrabajo indígena en las haciendas. La expansión de la hacienda y del volumen de la mano de obra debían ser, por lo tanto, paralelos.

\section{Un informe de 1795 dice que}

"no se les permite a los indios pescar en el río ni cazar ni buscar sus caballos cuando por las tierras que se les han de asignar... están inundadas de ganados de los pobladores (españoles) y éstos transitan por ellas, pescan, cazan, cortan maderas, etcétera".

Si el frente pionero avanza sobre los recursos naturales del indio, para éste la solución es integrarse -como lo propuso Anayaal mercado colonial; para los ganaderos la única forma de integración es radicarlos en puntos bien controlados, fuertes o reducciones. La movilidad debe ser erradicada por completo: si partidas de indios se

30 Biblioteca y Archivo del Colegio Franciscano de Salta (en adelante BACFS), Caja de Orán. Informe de L. García, 1795. 
desplazan sin supervisión militar, deben en todos los casos comunicarlo a las autoridades según lo estableciera en su momento el gobernador García Pizarro, con el argumento de que siendo "recién conversos se les recela infidelidad". ${ }^{31}$

Pero la concentración nuclear de indios hace que reduzcan su acceso a los recursos y se vean así obligados al robo de ganado. Para la ley, los indios eran casi siempre vulgares ladrones capaces de producir "invasiones y estragos en la frontera". La justificación para "pacificarlos" y "evangelizarlos" estaba cumplida. Para dominarlos, y en número suficiente para producir el volumen de ganado y manufacturas ganaderas esperadas por los pioneros, era necesario un sistema más orgánico que la maloca, el presidio y la expedición punitiva. La reducción religiosa pretendió dar otra respuesta al problema.

\section{Fortines misioneros y misiones fortificadas}

Hemos anticipado que en el Chaco las misiones jesuitas cumplieron un rol cualitativamente pobre, en ningún momento lograron esa autonomía que parece haber sido siempre el objetivo preciado por los misioneros. Más fuertes que reducciones, se mantuvieron mucho tiempo por el sostén y la vigilancia de las autoridades coloniales más próximas y, desde el interior del Chaco, bajo la continua presión de las poblaciones guaykurúes - tobas y mocovíes-.

De esta manera, la historia de estas desdichadas reducciones parece desdecir argumentos corrientes sobre su papel en la función defensiva del sistema urbano-colonial tucumano. Sí es visible, desde el punto de vista indígena, su función de refugio de las poblaciones no guaykurúes que, fugitivas de la guerra interétnica, aceptaron (sin entusiasmo, al decir de sus frecuentes fugas) la tutela española. ${ }^{32}$

31 Idem.

32 Este parece ser, en efecto, el único rol de las misiones: garantizar el acceso a la fuerza de trabajo constituida por indígenas migrantes de la guerra. Una recorrida por las zonas de instalación desdice inmediatamente esa presunta función "defensiva". 
En el XVIII se pone en marcha una rumbosa política de misionalización prácticamente sin antecedentes en esta zona. El protector general de naturales J. Gregorio de Zamudio fundamenta el rol histórico de la misión:

"que sea útil a los indios no se puede negar pues reducidos a pueblo conseguirían salir de ser fieras silvestres y serán enseñados a la vida sociable y política y de este modo se facilita el que vengan en conocimiento y abracen la verdadera fe que es el fin tan deseado de nuestros monarcas". ${ }^{33}$

El sistema misional-militar se ve envuelto durante todo el siglo en la turbulenta guerra interétnica del Chaco. El marco general lo brinda la casi incontenible expansión toba-mocoví hacia la cuenca del Bermejo superior que empuja a lules y vilelas sobre los territorios coloniales del Salado superior. En la primera década del XVIII, por ejemplo, los mocovíes desalojan a los vilelas de la reducción de Balbuena. Los gobernadores del Tucumán (desde 1782 los gobernadores-intendentes de Salta) apelan de nuevo a la expedición punitiva y a la fortificación pero nada parece de veras efectivo.

Una presentación sucinta de estos acontecimientos dará una idea aproximada de las dificultades con que la sociedad colonial debió enfrentarse para adscribir mano de obra indígena, bien que el desplazamiento no del todo voluntario de tribus derrotadas hacia los fortines permite aprovecharlas como reservas de mano de obra.

Los mocovíes se habían adueñado tempranamente del ángulo formado por el Salado y el Bermejo. Cazadores ecuestres, organizados en grupos patrilineales y expertos estrategas, impusieron su hegemonía en todo el Chaco austral durante el XVIII. En 1710 Urízar encabezó una masiva excursión punitiva integrada por 1.300 hombres; ${ }^{34}$ pudo infligirles una derrota parçial que le permitió juntar cuatro mil familias de malbales (la cifra parece excesiva) en los fuertes de Balbuena y Miraflores, sobre la costa oriental del Sala-

33 AGN, Interior, 5-10. Nota al virrey, 27 de marzo de 1778.

34 Garavaglia, Juan Carlos: La guerra en el Tucumán..., pág. 22. 
do. Algunos de ellos, remitidos a Buenos Aires, escaparon y regresaron a su país; más adelante otros grupos de malbales fueron reducidos en Macapillo, sobre el río Pasaje.

En 1710 se edifica el fuerte de Centa sobre el Bermejo ${ }^{35}$ cuando se hace contacto con los distintos etnogrupos vilelas radicados en la margen derecha del Bermejo medio. En 1721 el jesuita Patiño se interna en el Pilcomayo con poco éxito. ${ }^{36}$

En 1735, cuatro años después de la entrada de Arache, los vilelas trasplantados al Salado son concentrados en San José de Petacas ${ }^{37}$ mientras los mocovíes baten las fronteras salteñas, matando y cautivando medio millar de habitantes. ${ }^{38}$ Este asedio induce crueles expediciones de castigo; en 1742 el gobernador Montijo, que las ha organizado, funda el fuerte-reducción de Ortega en el Salado. ${ }^{39}$ Poco después, en 1750, el gobernador Martínez de Tineo ordena la instalación de cuatro nuevos fuertes: Río Negro, Tunillar (también llamado Piquete), San Fernando del Río del Valle y Pitos. Con esta nueva cadena de fortines se abandonan los antiguos antemurales de Ledesma, San José y Cobos. ${ }^{40}$

35 Castro Boedo, Emilio: Estudios sobre la navegación del Bermejo y colonización del Chaco. Buenos Aires, 1873, pág. 185.

36 Patiño, R. P.: Expedición al Pilcomayo, en AGN, Documentos de la Biblioteca Nacional, leg. 510, doc. 8137. También Aguirre, R. P.: Instrucción del Superior de la Compañía de Jesús a los padres expedicionarios del rio Pilcomayo, en AGN, BN, leg. 354, doc. 6170 .

37 Kersten, Ludwig: Las tribus indígenas del Gran Chaco hasta fines del siglo XVIII (1905) UNNE, Resistencia, 1968, págs. 92-93.

38 AGN, Interior, 5-10. Lapa, Antonio: Diario exacto y fiel de los acaecimientos sucedidos en la entrada al Gran Chaco Gualamba, 1776. Hay otro documento de similar contenido en AGN, BN, leg. 311, doc. 5099, titulado Diario de los acontecimientos sucedidos durante su viaje al Gran Chaco. Este texto fue publicado en la "Revista de la Biblioteca Nacional", Buenos Aires, 1954, tomo XXIII, n. ${ }^{\circ}$ 56, págs. 477-499. Lapa escribió en 1779 un Diario de su Segundo Viaje al Chaco. AGN, BN, leg. 311, doc. 5100.

39 Castro Boedo, Emilio: Estudios sobre la navegación..., pág. 185.

40 Un informe de Martínez de Tineo de 1750 agrega los fuertes de Santa Bárbara, Los Dolores y el pueblo de Mataguayes, según carta del 16 de octubre de 1750. (Archivo Nacional de Bolivia, 1756.112 en Garavaglia, Juan Carlos: La guerra en el Tucumán..., página 31, nota 6). Véase Martínez de Tineo, Juan Victorino: Diario de lo acaecido en varias jornadas hechas al Chaco con especificación de las leguas que se caminaron, en AGN, BN, leg. 98 , doc. 85 bis. 
La misión de San Esteban de Miraflores queda vacía durante la primera mitad del XVIII, pero en 1752 sus neófitos lules vuelven. El año anterior lules-isistinés y lules-tokistinés se radicaron en la misión gemela de Balbuena ${ }^{41}$ que sería trasladada a un nuevo sitio en $1765 .{ }^{42}$ Aunque el repliegue de los lules sobre la frontera oriental del Tucumán apresura su proceso aculturador, todavía en el XVIII viven restos aislados en las estepas orientales del Salado, sometidos siempre a la activa presión de tobas y mocovíes.

Esta misma presión que los tobas ejercen a lo largo del Pilcomayo comienza a desplazar las parcialidades vilelas de norte a sur logrando que en el período 1767-1780 todas ellas se hayan corrido al sur del Bermejo. ${ }^{43}$ Diez años después, Cornejo encuentra wichíes sólo en la banda norte del río mientras los vilelas quedan casi por completo reducidos en las misiones del Salado.

La Compañía de Jesús había intentado la misionalización según el modelo triunfante en Moxos, Chiquitania y Paraguay pero sus resultados fueron en el Bermejo infinitamente más modestos. Después de su expulsión (1767), los franciscanos, los seglares y los gobiernos laicos se preocuparon por consolidar la frontera militar pero la desorganización ya conocida y la corrupción abortaron la empresa.

La misión de San Ignacio sobre el río Ledesma, que los jesuitas instalaron en 1756 con catecúmenos wichíes, llegó a tener 600 habitantes en el momento de su expulsión. ${ }^{44}$ Se encargan de San José de Petacas en 1757, mudándola al Salado cuatro años después y en 1763 - siendo gobernador su antiguo aliado Campero- fundan Macapillo y rehabilitan Ortega, poblándola con vilelas procedentes del sur del Bermejo. ${ }^{45}$

Schindler ha sostenido que las misiones jesuitas llenan una doble función: por un lado, disminuyen substancialmente el número de

41 Kersten, Ludwig: Las tribus indigenas..., págs. 92-93.

42 Jolis, José: Ensayo sobre la historia natural del Gran Chaco, 1789. UNNE, Resistencia, 1972, pág. 324.

43 Morillo, Francisco: Diario del viaje al río Bermejo, 1780. Colección De Angelis, Buenos Aires, 1836.

44 Jolis, José: Ensayo sobre la historia..., pág. 324.

45 Ídem. 
ataques en los que participan indios sedentarios, pero más aún, las reducciones se instalan a menudo justo en los pasos de ataque de las tribus ecuestres protegiendo a los colonos blancos. ${ }^{46} \mathrm{Se}$ trata, a nuestro juicio, de una visión optimista que los hechos parecen no confirmar; puede que así haya sido en Paraguay pero no en el Chaco. La topografía de la región nos dice con claridad que los pasos de ataque eran muchos y complejos y que un breve rosario de empalizadas apenas pobladas era incapaz de frenar los ataques. Si los jesuitas apelan a la evangelización es porque se pueden organizar núcleos sedentarios con indios fugitivos ensayando algún "efecto demostración", pero apenas brindan protección alguna a los centros urbanos coloniales.

Una Visita de $1771^{47}$ ordenada por el Capítulo XIV del Nuevo Reglamento de Sisa - cuyo Capítulo IX prevenía el repartimiento que debía hacer en favor de los aborígenes- releva la población de las seis reducciones cuatro años después de haberse marchado los jesuitas. El relevamiento utiliza distintas categorías de clasificación:

POBLACIÓN DE LAS MISIONES DEL SALADO CLASIFICADA POR SEXO

Reducción

San José de Petacas

Miraflores

Ortega

Balbuena

Macapillo

San Ignacio de Tobas
Varones Mujeres

182

153

143

65

152

47

160
77

128

30

172

Total

375

296

142

280

46 Schindler, Helmut: Equestrian and non-equestrian indians of the Gran Chaco during the colonial period. Berlin, 1985. (Gedenkschrift Gerdt Kutscher, Teil 2) "Indiana”, 10, pág. 459.

47 AHPJ-ARR, leg. 2. Visita de reducciones de 1771. Véase también Visita a los Fuertes y Reducciones de la Frontera de la Jurisdicción de la Gobernación-Intendencia de Salta, 1787. AGN, Interior, 24-11. Y el relato de Juan Antonio Moro, Fuerte de San Fernando, 11 de julio de 1799, en AGN, Justicia, 40-1176. 
POBLACIÓN CLASIFICADA POR ESTADO CIVIL Y CONVERSIÓN

Reducción Casados Solteros Solteras Viudos Viudas Cristianos Infieles

\begin{tabular}{lrrrrrrr}
\hline Petacas & 156 & 107 & 89 & 8 & 15 & 375 & $15^{*}$ \\
Miraflores & 112 & 74 & 76 & 13 & 21 & 296 & - \\
Ortega & 88 & 18 & 26 & 3 & 7 & 142 & - \\
Balbuena & 148 & 71 & 49 & 7 & 5 & 280 & - \\
Macapillo & $(47$ varones y 30 mujeres $)$ & & 77 & $100^{*}$ \\
Tobas & $(160$ varones y 172 mujeres $)$ & & 272 & 60
\end{tabular}

* No discrimina por estado civil ni sexo.

La población total del sistema era de 1.617 habitantes, de los cuales 1.442 eran considerados cristianos. Ese número de habitantes se reduce a 700 en 1787 . Esta reducción del 57 por ciento en 16 años marca bien a las claras el descalabro de la gestión postjesuítica. Es precisamente el período cuando la presión toba-mocoví aumenta, pues ni franciscanos ni seglares planifican nada nuevo. Los Cabildos insisten en fortalecer los enclaves fronterizos, mudarlos a sitios más seguros, pero en general las autoridades centrales no brindan apoyo financiero. De algún modo, la guerra es una empresa privada y son los hacendados y mercaderes quienes deben costearla. Las guarniciones padecen miseria y tampoco hay curas suficientes para atender "las necesidades espirituales". Hay misioneros que se prodigan viajando de una misión a otra. Pero así como las autoridades hacen la vista gorda, muchos hacendados no encuentran motivo para ceder una parte de sus ganancias y atender sus obligaciones militares. Las pasturas orientales no se necesitan tanto como sus habitantes. ${ }^{48}$

Más aún, puede sospecharse que la abrupta declinación del número de ganados no sólo se deba a negligencia administrativa sino a ventas ilegales realizadas a puntos importantes del circuito mer-

48 Una descripción de la resistencia a financiar la guerra en Garavaglia, Juan Carlos: La guerra en Tucumán..., págs. 24-27. 
cantil, probablemente en jurisdicción portuguesa, o a simple y llana depredación de los hacendados.

Las dos últimas misiones del Chaco fueron Santa Rosa, fundada en 1774 por Matorras sobre el Salado, ${ }^{49}$ y Centa, establecida por Francisco Gabino Arias en 1779 con pobladores wichí-vejoz en la confluencia de los ríos San Andrés y Centa. ${ }^{50}$ La multiplicación de reducciones, en el este y el oeste del Chaco, no significan que el sistema se haya consolidado sino que, al contrario, ninguna de ellas logra afianzarse definitivamente.

Nos referimos antes a la probable depredación de los ganados jesuitas: alguien denuncia que el corregidor Juan Adrián Cornejo, en alianza con el gobernador Campero, sacó de las reducciones de Ortega y Balbuena

"porciones de ganados, mulas, jabón y otros bienes sin habérseles hecho el debido reintegro".

La Visita de 1771, que contiene esta denuncia, nos brinda además información económica: ${ }^{51}$ en 1768 la misión de los tobas tenía 2.232 vacunos, 70 bueyes para arado, 28 yeguas y 14 mulas lo que nos hace pensar en una incipiente inserción en el comercio regional. Tres años después el doctrinero franciscano Francisco de Arze no encuentra ya nada, atribuyendo esta decadencia al

"ningún régimen que hubo en la dicha reducción y falta de un celoso e inteligente mayordomo o capataz que cuidase de dichas haciendas y su consumo arreglado al régimen que observaban los dichos jesuitas, como también el haberse salido el que éstos dejaron por no habérsele dado el sueldo que ganaba".

Otra Visita, ésta de 1779, se refiere al "infeliz estado" de las seis reducciones. ${ }^{52}$ Pero el resultado más lamentado fue la fuga de la mayor parte de los tobas al monte "para alimentarse con sus fru-

49 Castro Boedo, Emilio: Estudios sobre la navegación..., pág. 187.

50 Morillo, Francisco: Diario del viaje..., pág. 139.

51 AHPJ, ARR, XL, leg. 2.

52 fdem. 
tos". El gobierno hizo lo posible por restablecer la misión en su esplendor proveyéndola de herramientas, semillas y algunas reses, limpiando la acequia que les llevaba el agua, apoyándose, para todos estos gastos, en las sisas de San Salvador de Jujuy. Un panorama parecido descubren los visitadores en las demás reducciones.

Un día, el administrador franciscano de Ortega contrata con un vecino de San Miguel de Tucumán, José Caenzo, la reconstrucción de la iglesia; le pagará con 500 cabezas de ganado vacuno. Este tipo de inversión, en el deteriorado paisaje de las reducciones parece inadecuado, inoportuno. Las explicaciones al uso son de todo tipo, en Balbuena los indios se habían dispersado por el "genio veleidoso" del doctrinero y

"el poco agrado del corregidor que se les puso y sus tenientes y delegados que tiraban a menoscabar sus haciendas".

Menoscabo intencional más que negligencia. Los lules-isistinés y los lules-tokistinés resolvieron volver al reducto sólo cuando el gobernador les prometio reintegrarles el valor de lo que les habían sacado.

Depredación del ganado de los jesuitas por funcionarios y hacendados corruptos, gastos inútiles, desavenencias personales y éxodos de catecúmenos caracterizan el período postjesuítico. El sistema ya no sirve para reunir fuerza de trabajo, él mismo es ahora el botín de los hacendados. No falta quien todavía crea que la propagación de la lengua castellana entre los indios (siguiendo la propuesta del arzobispo de México) sirva como remedio de males. Nadie parece reparar en la falta de doctrineros. Morillo encuentra unos sesenta vilelas-atalalá que han abandonado Macapillo porque el franciscano que los atendía, Antonio Lapa, se había marchado. Los indios prometen volver sólo cuando su misionero regrese. ${ }^{53}$ También Arias encuentra a los quejosos atalalá, que insisten en reorganizar la misión de Macapillo. Ellos mismos se ofrecen a cooperar en la construcción de capillas, siempre y cuando se les regalen carne y ropas. ${ }^{54}$

53 Morillo, Francisco: Diario del viaje..., pág. 146 v.

54 Arias, F. G.: Diario y descripción..., f. 26 v. 
Pero todavía queda entusiasmo para un nuevo proyecto, paralelo al deterioro de las misiones de frontera: la conquista militar y espiritual del Bermejo medio. Se cree que dos o tres misiones bien adentro del Chaco pueden abortar los ataques tobas en su raíz, cortar el éxodo de vilelas hacia el sudoeste y postergar el ingreso a la cuenca de los pueblos chorotes y pilagás, presionados a su vez desde el norte del Pilcomayo por los lengua-maskoy.

En su época, los jesuitas habían proyectado la reconstrucción de la antigua ciudad de Concepción del Bermejo como un punto avanzado para la "pacificación" del Chaco central.

Este criterio es remozado poco después de su expulsión cuando en 1774 se funda la misión de Santiago de la Cangayé en la costa meridional del Bermejo. Allí el gobernador Matorras logra persuadir al cacique Paykín para que se concentre con su gente bajo la guía espiritual de los franciscanos, por supuesto. Cangayé, ubicada a sesenta leguas de la ciudad de Corrientes, recibió 1.000 wichíes, 300 mocovíes, 400 vilelas y 500 tobas. ${ }^{55}$ En diciembre de 1780 llegan a Cangayé 2.000 tobas y mocovíes más, lo que obliga a despedir de inmediato a los wichíes. En 1797 sólo quedaban en la nueva misión los mocovíes. ${ }^{56}$ En el ínterin se reciben neófitos de la sureña San Pedro de Santa Fe perseguidos por la guerra abipona que se hizo endémica en las últimas décadas del XVIII.

Casi gemela a Cangayé, Morillo y el franciscano Lapa fundan en 1781 la misión de San Bernardo de Tobas, también en el Bermejo medio. Reúnen allí unos 500 tobas, residuos meridionales de la gran nación toba que entonces se desplaza amenazante hacia el norte y el noroeste. ${ }^{57} \mathrm{Al}$ año siguiente se levanta otra misión entre los tobas, en Naranjai, pero tres años después sus neófitos la destruyen dándose a la fuga. Cuando en 1787 se restablece frente al presidio de San Antonio con el nombre de Rosario, los tobas vuelven a poblarla pacíficamente, pues su proximidad al río Paraguay y

55 Ibidem, f. 29 v.

56 Basabe, Manuel de: Informe sobre las misiones del Chaco. AGN, Interior, 40-12.

57 Kersten, Ludwig: Las tribus indigenas..., págs. 60-61. Un plano de la reducción de San Bernardo puede estudiarse en AGN, Guerra y Marina, 4-6. 
a Asunción la convierte en un activo centro de intercambio comercial. ${ }^{58}$ Pero en 1797 se marchan de nuevo, simultáneamente con el éxodo de otros guaykurúes, los mbayá de Villa Real de la Concepción. Sólo los mocovíes permanecen en el puesto de Los Remolinos.

Estas idas y venidas están estrechamente relacionadas con la economía de las sociedades indígenas: períodos de escasez promueven la expansión y la guerra, y períodos de abundancia restablecen la paz y mueven a los indígenas a comerciar en los enclaves coloniales donde saben que a cambio de sus propios productos pueden conseguir instrumentos de hierro.

Para el gobernador Ribera, el fracaso de las misiones debe atribuirse a la falta de dinero (es natural que lo haga así porque puede argumentar mejor su sempiterno reclamo). ${ }^{59}$ Todavía en 1808 el apoyo financiero luce por su ausencia. Al denunciar la pobreza que agobia a la misión de San Ignacio de los Tobas, el protector de naturales reclama la ración de carnes que antes se recibía.

Pero no hay arreglo y los indios vuelven al monte desconfiando de los misioneros. En algunos momentos, las autoridades ceden y envían algo: las reducciones reciben ganado o se reparten a los caciques cuñas de hierro o cuchillos. Hasta se les envía un vacunador. ${ }^{60}$ Hay fuertes que reciben sombreros, gualcas, cuchillos, tucuyos, bayetas y uniformes para los principales de cada parcialidad. Se trata, mínimamente, de mantener satisfechos a los "indios mansos" que hasta suelen acompañar y ayudar a los españoles en sus entradas al Chaco. ${ }^{61}$ Pero estos esfuerzos no contienen el desaliento general. Muchos, como el conversor de Centa en 1792, se quejan del poco resultado del sistema misional. ${ }^{62}$

58 AGN, Guerra y Marina, 7-9. Parte del 31 de agosto de 1781 pidiendo personal para las reducciones.

59 AGN, Justicia, 20-554. Según los informes de fray Francisco de Altolaguirre, 11 de mayo de 1786, Pedro Melo de Portugal del 9 de enero de 1787 y de Félix Sánchez de Celis, 6 de julio de 1787.

60 AGN, Interior, 41-3.

61 AGN, Justicia, 51-1497 y Guerra y Marina, 33-29 (1802).

62 Cuenca, Sebastián: Reducción de Nuestra Señora de las Angustias de Zenta, 8 de agosto de 1792, en BACFS, Caja de Orán. 
Algunos, en cambio, siguen optimistas con el proyecto militarmisional. El gobernador García Pizarro cree firmemente en una ocupación efectiva y permanente del valle de San Francisco, donde opera una rústica industria azucarera, adivinando el valor potencial que los extensos pastizales de la región prometen a la cría del ganado. Por esa razón funda Nueva Orán (1794) cerca del sitio de la antigua Guadalcázar. ${ }^{63}$

A pesar de las muestras de optimismo oficial, el éxodo desde las misiones del Bermejo crece y en 1799 grupos vilelas comienzan a desplazarse fuera de sus refugios. El cacique Kolompoto y su gente, proveniente de Macapillo y Santa Rosa, se marcha al sureste, al pueblo de San Gerónimo de Abipones. ${ }^{64}$ Ese año tobas y mocovíes abandonan Cangayé y San Bernardo. El cacique Nachingin se muda a Santa Fe. No está claro el porqué de estas migraciones al sur. Un funcionario explica que las reducciones de San José de Petacas y Santa Rosa se han extinguido por hambre y que por idéntica razón la gente de Macapillo huyó a Miraflores. ${ }^{65}$ Juan José Ortiz, fiscal y protector general, escribe en 1807 :

"si en la reducción se les sitia por hambre y por otra parte la fertilidad del Chaco y sus parientes los atraen, ellos, como bárbaros, atenderán al bien temporal con abandono de sus almas". ${ }^{66}$

Parece natural que en estas condiciones nadie acusaría a los aborígenes de poca disposición para aprender a vivir en pueblos o a evangelizarse. Los indios ven en la reducción la firme posibilidad del sustento diario sin necesidad de las largas correrías que exige la economía tradicional, correrías que ahora tienen un escenario hostil; también se sabe que los indios concentran la oferta de sus productos en las reducciones como rudimentarios mercados locales.

63 Castro Boedo, Emilio: Estudios sobre la navegación..., pág. 188.

64 AGN, Interior, 40-12. Prudencio M. Castañadu, teniente gobernador de Santa Fe, al virrey Olaguer, 5 de marzo de 1799. 1802.

65 AGN, Justicia, 40-1176. Nicolás León de Ojeda a M. G. Villota, 3 de abril de

66 AGN, Interior, 60-1. Informe de J. J. Ortiz, 10 de marzo de 1807. 
La labor misionera se hace penosa, nadie cree en su éxito, los pocos doctrineros no abandonan los viejos prejuicios antiindígenas y las autoridades hacen oídos sordos a los pedidos de auxilio. Un vago control de las fronteras y el reclutamiento de contingentes mínimos satisface las necesidades de los hacendados. Lo único inquietante es, por supuesto, la amenaza toba-mocoví de modo que sólo con lograr la reducción de estos pueblos, todos los demás se mantendrían alejados. Ortiz le adjudica a la misión de Ledesma

"la paz con la numerosa nación toba del Chaco, que en mantenerla donde se halla situada consiste la señal de paz con los cristianos. Sirve de antemural para con las otras naciones de infieles que todas temen al toba".

Pero vimos que también Ledesma fue alguna vez abandonada. El ciclo de esperanza y ruina se repetía monótonamente sin que nada permitiera terminar de una vez con el desorden de las guerras tribales en el interior del Chaco.

\section{Las guerras interétnicas en la estrategia colonial}

Schindler ha llamado la atención sobre el rol del caballo en la expansión guaykurú; que éstos lo utilizaran y sus vecinos wichí, lules o vilelas no, parecería determinar la estrategia expansionista y agresiva de aquéllos sobre el territorio de éstos. Pero también la severa presión de los cazadores montados sobre la frontera pionera blanca; en su opinión - y en contra de lo sostenido por Susnik ${ }^{67}$ no fue la adopción del caballo lo que volvió guerreros a los guaykurúes sino que adoptaron el caballo porque la guerra ya formaba un dato clave de su cultura. ${ }^{68}$ Nosotros creemos que formaba un mecanismo alternativo al intercambio pacífico y no hay determinantes específicamente culturales que lleven, más allá de toda raciona-

67 Susnik, Branislava: Dimensiones migratorias y pautas culturales de los pueblos del Gran Chaco y de su periferia (enfoque etnológico). "Suplemento Antropológico". Asunción, 1972, vol. 7, n.' 1-2, pág. 93.

68 Schindler, Helmut: Equestrian and..., pág. 456. 
lización práctica, a vivir la guerra como un sino fatal. ${ }^{69}$ El dato saliente que moviliza esta densa estructura étnica del Chaco centrooccidental es la expansión toba, la conquista de pescaderos, cotos de caza y zonas nuevas de recolección. Susnik asegura que al principio esta tribu ocupó el espacio que los mbayá dejaron libre al sur del Pilcomayo, luego de migrar al Alto Paraguay. Hostilizando a los enimagá-cochaboth, remontaron el gran río asentándose en Centa, Orán y todas las regiones linderas del Pilcomayo superior, hasta encontrar su límite expansivo en la Chiriguania. ${ }^{70}$

Pero más allá de la movilidad que el caballo le brindó a los guerreros guaykurúes, debe notarse que los colonos españoles excitan sistemáticamente la guerra interétnica, al principio - como hemos descrito en la maloca - para conseguir esclavos, luego para lanzar unas tribus contra otras mediante alianzas inestables y restablecer así el equilibrio, otras veces, en fin, para protegerse con unos de otros. Lo reconoce Arenales:

"los conquistadores agregaban en su favor la ventaja de formar alianzas con los vencidos e instigar por este medio nuevas guerras y disensiones, siempre sangrientas entre los naturales".

\section{a) La "amenaza" wichi en el norte}

Un área de peligroso conflicto se despliega en el Bermejo superior entre tobas y wichí. Los primeros son aliados necesarios para frenar a los últimos, bien que unos y otros trabajan pacíficamente en las haciendas algunos meses por año. ${ }^{72}$ Hemos visto ya el buen concepto que los colonos tienen de los wichí "pacificados". Hacia

69 Se caería de este modo en las insostenibles tesis de P. Clastres sobre "la búsqueda de prestigio" por la guerra o "la pulsión de muerte", una desdichada generalización psicoanalítica que podría describir toda sociedad humana y no solamente a los "primitivos" (Cf. Pierre Clastres: Malheur du guerrier sauvage. "Recherches d'Anthropologie politique". Paris, 1980, citado por Garavaglia que acepta esas tesis, La guerra en el Tucumán...).

70 Susnik, Branislava: Dimensiones migratorias..., pág. 93.

71 Arenales, José de: Noticias Históricas..., pág. 100.

72 AGN, Interior, 60-1. J. J.: Ortiz al alcalde Agurrinaga, 3 de noviembre de 1807. 
1780 Morillo señala un enfrentamiento permanente entre los propios wichí: wichí-noktén o tataguayos y wichí-vejoz:

"son todos de una misma nación pero enemigos declarados los del sur (del Bermejo) con los del norte y suelen decirles los del sur 'mataco bueno, mataguayo malo' y al contrario los del norte". ${ }^{73}$

Arias nos presenta a los wichí-noktén como una "nación innumerable", hay un millar en la frontera de Salta y otra "gran multitud" confinante con los chiriguanos. ${ }^{74} \mathrm{Se}$ les teme por su carácter belicoso, su destreza en el uso de dardos, flechas y macanas, ${ }^{75}$ y su costumbre de decapitar los cadáveres y desollar el cráneo. ${ }^{76}$ Exhiben una buena estructura militar basada en un modelo semejante al chiriguano, un tipo de cacicazgo segmentario dirigido por capitanes, a los cuales los españoles llaman a veces "mandones". Estas bandas tenían en apariencia una baja tasa de natalidad. ${ }^{77}$

\section{b) El conflicto toba-chiriguano}

Otro frente un poco lejano pero que repercute en la cuenca superior del Bermejo actúa en la frontera chiriguana-toba enardecida por la furtiva presencia portuguesa. En 1766 varios tobas se refugian en las aldeas chiriguanas de Caruruti y Tarairi, al noroeste de Salinas, escapando de los portugueses. ${ }^{78}$ Pero en 1778 Francisco Robles informa que estos andan "muy amistados" entre los tobas, sorprendiéndose de que no los devorasen, dada su fama de antropófagos. ${ }^{79}$

73 Morillo, Francisco: Diario del viaje..., fs. 142-142v.

74 Aruas, F. G.: Diario y descripción..., fs. 15 v. y 16 v.

75 Luz, Rafael de la: Censo de parcialidades Matacas en el Fuerte del Río del Valle. AGN, Justicia, 40-1176.

76 AGN, Hacienda, 100-2613. Rafael Bechier a Rafael de la Luz, 26 de octubre de 1801.

77 Luz señala 423 soldados y 852 mujeres y niños, casi un niño por soldado considerando convencionalmente matrimonios completos, divididos en ocho cacicazgos.

78 Saignes, Thierry: L'Indien, le portugais et le jésuite: alliances et rivalités aux confins du Chaco au XVIIle. siecle. "Cahiers d'Amérique Latine", Paris, 1974, n.os 9-10.

79 AGN, Interior, 6-13. Francisco Robles, 22 de diciembre de 1778. 
Otro testimonio dice lo contrario. Es el caso de Teodoro Trelles que relata a un corregidor como un anciano chiriguano, capitán de Aguatiri, le contó que 300 portugueses habían combatido contra los tobas. Derrotados, éstos pidieron auxilio a los Vilelas pero ambos pueblos fueron masacrados en septiembre de $1778 .^{80} \mathrm{El}$ enfrentamiento entre tobas y chiriguanos comienza muy al principio del XVII; ya en 1609 el padre Diego de Torres ubicaba a los primeros cerca de Tarija. ${ }^{81}$ Su gran expansión los lleva al lejano borde septentrional del Chaco donde en 1741 asaltan la reducción de San Ignacio de Zamicos. ${ }^{82}$ El pico de máxima intensidad se produce a fines del siglo: en 1793 la ofensiva Toba sacude toda la Chiriguania, asolando las aldeas de Guacaya, Parapiti, Chimeo, Izozog y Taregre. ${ }^{83}$

\section{c) La “amenaza" vilela sobre la frontera del Salado}

Vimos que la expansión toba-mocoví empujó a los vilelas contra la frontera colonial. Organizados en cacicazgos fragmentarios no pudieron resistir, como los wichí-noktén o los chiriguanos, el proceso dominador y aculturador del blanco. Sin embargo, Arias los presenta como naciones belicosas, sobre todo a las parcialidades que siguen al capitán Atakampibap, del subgrupo vilela-chunupí. En 1802, comprimidos por los tobas, los vilelas amenazan los fuertes del Valle Grande y Pitos. ${ }^{84}$ ¿Amenaza real, desborde desesperado u oportunidad de denunciar a los derrotados migrantes como una amenaza potencial para justificar su esclavitud en las haciendas?

80 AGN, Interior, 6-13. Gabriel Pérez Camino, informe fechado en Mollene el 20 de diciembre de 1778.

81 Susnik, Branislava: Dimensiones migratorias..., pág. 130. de 1793.

82 AGN, Justicia, 32-932. Informe del subdelegado de Tomina del 31 de octubre

83 AGN, Hacienda, 109-2809. Miguel de Robledo al comandante del Fuerte del Río del Valle, 1802. Sobre la problemática en esta región consúltese Haedo, Felipe de: Octavo informe con las fortificaciones de los portugueses en las fronteras del Virreinato del Perú, medios de internarse, de atacarlas, noticias de los ríos Pilcomayo, Bermejo y Salado, AGN, BN, leg. 191, doc. 1989.

84 Comando de Armas a la Intendencia, 5 de septiembre de 1807. 
En 1807 el comandante de armas de Salta hace público un parte proveniente del fuerte de San Bernardo:

"que descubre el alevoso y abominable modo con que Chinchin y el capitán Guacas, caudillos de Ocoles, Pasaynes y Malbalaes (todos ellos subgrupos vilelas) intentan bajo el colorido de venir a hacer las paces con el español invadir por sorpresa la frontera del río del Valle". ${ }^{85}$

\section{Balance final del proceso misional-militar en la frontera}

Se ha visto ya la debilidad estructural de las autoridades militares y eclesiásticas para impedir la guerra interétnica y su decisión, entonces, de utilizarla en su provecho. Llegado el punto de preguntar hasta dónde la guerra sirvió para adscribir mano de obra se debe recorrer otra vez las cifras indicadas de indios reducidos, bien que se trate de cifras estimadas y bastante variables.

Sobre el grado de aculturación logrado en esas poblaciones baste consignar el fracaso de los jesuitas y de quienes les sucedieron. El mismo robo de indios esclavizados que unos hacendados cometen contra otros muestra que el sistema militar-reduccional no alcanzó a satisfacer la demanda del mercado de trabajo. Entonces sobrevienen las explicaciones y así dice Alós:

"valerse de reducciones es negocio inútil porque ya deben desengañarnos las muchas que hay en esta provincia (del Chaco) sin que de ellas se reporte utilidad alguna". ${ }^{86}$

$\mathrm{Ni}$ siquiera se puede impedir la penetración portuguesa en el Chaco ni limitar la omnipresente expansión toba. Según los españoles, la diplomacia ha fracasado por la inconstancia del indio. En 1797 Baldovinos acusa que si

85 AHS, Miscellanea o documentación varia, expediente 2.

86 Alós, Joaquín de: Informe al virrey Nicolás de Arredondo sobre el proyecto de poblar el Bermejo, 1790, editado en Exploración al Gran Chaco, "Revista Paraguaya". Asunción, 1899, pág. 20. 
"se quiere buscar a los indios con la suavidad y proponerles la paz se ríen; y en caso de pedir reducción y admitirla, pronto se da en el mismo escollo. Si quiere perseguirlos con la fuerza al instante hacen sus capitulaciones, pero en lugar de guardarlas, las rompen con más furia".

\section{Por su lado Segovia piensa que}

"escribir tratados de paz con unos infieles que ignoran lo que importa esa formalidad sería tomarse un ímprobo trabajo y dar ocasión al entretenimiento de buenos humores".

Cita el caso de la paz celebrada en San Antonio de Tobas, en contrato escrito y autorizado por escribano, luego refrendado por el Cabildo y que terminó al día siguiente con el incendio de la reducción y la fuga de los aborígenes. ${ }^{87}$

En su informe al gobernador, Ortiz resume lo que eclesiásticos como él, civiles y militares piensan sobre las dificultades de sedentarizar al indio:

"por naturaleza bárbaros no se gobiernan más que por la apariencia del bien presente. Para ellos, acostumbrados al ocio inseparable de su carácter, el trabajo es uno de los males que más sienten, por eso huyen tanto de él. Cuando se conchaban es por lo que reciben adelantado, de modo que un mes de servicio lo cumplen en tres o cuatro porque si un día trabajan, dos o tres descansan. En vano son discursos y esfuerzos para hacerlos conocer su bien, aferrados en las costumbres antiguas de sus padres. Sólo se llevan del bien aparente y que le es más fácil su ejecución. La pesca, la caza con el arco, meleadas, yerbas y raíces de los montes son las que les convidare a saciar su ocio porque no les cuesta trabajo el sembrarlas y antes recién mucho en recogerlas. Con ellas, les convida la fertilidad del Chaco y el contrario la reducción con hambres, trabajos y necesidades. ¿A cuál de estos bienes se aplicarán los indios?"

y sobre el sentido de reducirlos, agrega

"la reducción durará mientras haya cómo sostener a los viejos y párvulos en ella, que son los únicos que atraen a los que salen en búsqueda de su alimentos. Aquéllos se sostienen con el poco ganado que

87 AGN, Criminales, 42-10. 
ha quedado (después de la expulsión de los jesuitas) concluido éste se acabó la reducción, pues ya no tienen aliciente que les haga volver a ella". 88

Manuel de Basabe, por su lado, exhibe un escepticismo análogo respecto del curso rumboso de la misionalización; insiste en el viejo argumento de la pereza innata del indio, pero atribuye el fracaso a que permanecen

"en su patrio suelo donde forzosamente han de conservar ideas brutales con lo que ven de sus rivales y oyen de sus mayores".

Por ese motivo, las tribus hambrientas llegan a la misión, comen las provisiones y roban las caballadas; su comunicación permanente con los "infieles" impide que puedan "olvidar sus supersticiones y torpezas", algo contra lo cual el cura no puede luchar solo. Basabe ha creído que las reducciones servirían de aliciente a otros pueblos de indios pero su conocimiento "sobre la condición de los indios y circunstancias locales del Chaco" lo hacen pesimista. Propone congregarlos fuera de sus territorios, en zonas efectivamente dominadas por el poder colonial.

¿Sólo las dificultades técnicas y la poca confiabilidad del indio llevaban al fracaso del plan colonizador? Encarnando una corriente muy crítica de la política misional, Azara recomienda a las autoridades

"precaverse de todo gobernador y eclesiástico que trate de propaganda fide para no admitir jamás sus propuestas, por más ventajosas y cristianas que las pinten, porque sobre que seguramente todo esto es inútil y no ha tenido ni tendrá jamás un buen éxito, es vergonzoso dejarse engañar después de siglo y medio de experiencia por gente tonta o tal vez ambiciosa que por este camino no busca tanto lo que aparenta como sus adelantamientos". ${ }^{89}$

88 AGN, Interior, 60-1. J. J. Ortiz al gobernador, 20 de agosto de 1806.

89 Azara, Félix de: Informes sobre varios proyectos de colonizar el Chaco, 1799, en Colección De Angelis, Buenos Aires, 1836, pág. 418. Véase también del mismo autor el Informe sobre reducir los bárbaros del Chaco acompañado de documentos y pruebas, en AGN, BN, leg. 290, doc. 4500, fechado, como el anterior, en 1799. 
Matorras dice que no tuvo otra mira más que lograr el grado de coronel, según Azara, y lo mismo Francisco Arias. La expedición de León de 1791 — que veremos en seguida - fue un negocio particular

"de aquellos que suelen hacer con el rey, propuesto por uno que ignoro tenga caudal, oficio ni beneficio".

\section{La otra escena: mercaderes y relaciones comerciales}

Tierra de misionalización turbulenta y de hostilidades endémicas, el Chaco puede ser - como Chiquitos - escenario próspero para el comercio de larga distancia. Pero también en este campo los resultados son muy modestos. Las conocidas "entradas" de Filiberto de Mena (1764), Matorras y el padre Lapa (1774), la que este cura hizo solo (1776), la de Morillo (1780), la de Arias (1780-1781), la de Fernández Cornejo (1790) ${ }^{91}$ y la de otro Cornejo en 1799 constituyen empresas oficiales que conjugan la exploración geográfica, la estrategia militar y el esfuerzo misionero, es decir, las técnicas más aceptadas y de dominación de mano de obra. Pero hay iniciativas privadas que sólo pueden vincularse al interés mercantil.

Están, por ejemplo, el caso de Joaquín Legal y Córdoba que une en 1772 la misión de San Gerónimo de Abipones con Santiago del Estero, cruzando el Chaco Austral; el viaje del mercader yerbatero Manuel Victoriano de León que propone en 1791 navegar el Bermejo entrando al río Colorado y al puerto de Centa. En esta oportunidad, León pide como compensación un privilegio por diez años para llevar yerba del Paraguay a Salta. ${ }^{92}$

$\mathrm{Al}$ año siguiente, otro comerciante llamado Juan Manuel Piris (a quien en 1794 encontramos como comandante del presidio de $\mathrm{Cu}$ -

90 Azara, Félix de: Informes sobre varios..., pág. 424.

91 Fernández Cornejo, Juan Adrián: Sobre la necesidad de adelantar los fuertes de Salta y Jujuy, en AGN, Archivo y'Colección Andrés Lamas, leg. 8, 1780.

92 AGN, Guerra y Marina, 17-41. De León conservamos un Proyecto para fortificar y poblar cierta parte meridional del río Grande o Bermejo. AGN-BN, leg. 189, doc. 1880. 
rupaytí) ${ }^{93}$ propone cruzar desde Corrientes a Córdoba, empresa para cuyo éxito cuenta con el en apariencia sorprendente auxilio del cacique Nachilkin. En mayo llega a San Pedro de Mocovíes; en junio pasa por San Carlos y en julio alcanza Córdoba acompañado por tres jefes indígenas de Santiago.

Lo curioso es no sólo que Piris abre una causa judicial por contrabando sino que Joaquín Legal atestigua que trata muy bien a los indios y que éstos aman a Piris. En su Diario, éste confirma que tobas y mocovíes lo recibieron "con mucha alegría", que le convidaron con miel y algarrobato y que un mocoví que estaba mariscando le narró durante dos horas "las desdichas que pasaban". Otros mocovíes de Cangayé le comentan "la poca asistencia de sus curas". Otros de San Pedro le dicen que han abandonado el pueblo porque el capitán los aborrece y

"porque los daños que hacen los altaneros nos imputan ser nosotros cómplices en ello". ${ }^{4}$

El relato de Piris (o mejor, los testimonios indígenas que incluye) muestran el lado oculto de la documentación oficial. Hay una otra escena detrás del marco tradicional de una estepa boscosa, salvaje y desconocida, esporádicamente surcada por exploradores, militares y misioneros. Nos encontramos aquí con un espacio perfectamente recorrible, donde el viandante puede contar con el auxilio de los habitantes, que no sólo le abastecen o le guían sino que le hacen receptor de sus quejas. Hay también rutas establecidas y las principales ciudades del mundo colonial pueden unirse por expediciones bien provistas.

Visto en perspectiva ilustrada, esta demostración práctica de las facilidades de tránsito no deja de sonar como un proyecto de integración espacial en sentido moderno, que descarta, de paso, los métodos de integración violenta como el presidio o la reducción. Lo que Azara pone sobre el tapete no son sólo las ambiciones perso-

93 Alós, Joaquín: Informe al virrey..., pág. 42.

94 Piris, Juan Manuel: Diario del camino que emprendo desde Curupayti, jurisdicción de Corrientes, para las reducciones del Chaco, AGN, Interior, 33-8. 
nales de algunos jefes militares sino el interés mercantil que subyace larvado en los planes de fortificación y misionalización pero que surge más nítidamente en las empresas específicamente comerciales.

Por supuesto, ese interés mercantil trasciende la región chaqueña porque dejando de lado las eventuales riquezas de la zona, aún mal determinadas, ${ }^{95}$ lo importante del acceso (más que el dominio) de esas tierras las convertiría en espacio de comunicación entre el litoral, el Tucumán y el Alto Perú. La reconsideración del espacio chaqueño como vía de comunicación más que como escenario de conquista (militar o espiritual) aseguraría de paso la paz de la región ya que, indudablemente, los indígenas estaban más dispuestos a integrarse a intercambios comerciales libres que a trabajar como esclavos en las estancias o los cañaverales.

Azara, que ha criticado los proyectos de reducción militar o religiosa, propone

"establecer buen trato y comercio con dichos bárbaros para que por su propio interés conserven la paz, como vemos (que) sucede en el Paraguay con los payaguás y los guaná y en Buenos Aires con los pampas". ${ }^{96}$

Puede creerse que para la burguesía mercantil de Asunción una apertura al oeste a través del Chaco produciría efectos inmediatos con posibilidades de ampliar sus rutas de intercambio. Es posible, sin embargo, que los propios paraguayos no estuvieran tan convencidos de los beneficios de semejante contacto, lo reconoce Azara a raíz de la crítica que habían despertado entre ellos los impuestos exigidos por Alós a distintos pueblos del Paraguay para costear su expedición al Chaco en $1794 .{ }^{97}$

Estas opiniones divergentes sobre el valor del Chaco como comunicación con las zonas más mercantilizadas del espacio colonial no consideran en ningún momento la productividad de la región o

95 Véase Arias Hidalgo, José Antonio: Descripción Geográfica de toda la provincia del Chaco, AGN, BN, leg. 312, doc. 5101.

96 Azara, Félix de: Informés sobre varios..., pág. 423.

97 Representación del Cabildo de Asunción sobre la expedición al Chaco promovida por Joaquín de Alós: Exploración del Gran Chaco, "Revista Paraguaya", Asunción, 1899. 
el volumen de sus recursos naturales. ¿Qué se sabe entonces sobre ese tema? Azara sostiene que no hay allí ni riquezas mineras ni sal ni posibilidades de pastoreo extensivo. ${ }^{98}$ García de Solalinde, que vivió un tiempo como pionero en la zona, intenta persuadir al virrey de las ventajas de un poblamiento estable sobre todo en momentos en que "acosados del hambre y la necesidad" los tobas han pasado al norte del Bermejo, sin fuerzas para amenazar a sus vecinos. Solalinde cree que los recursos chaqueños justifican su poblamiento: madera abundante (él mismo había explotado durante un par de años un obraje maderero en El Palmar de la Laguna Grande); posibilidades de pastoreo y una laguna de sal a 50 leguas de la desembocadura del Colorado. ${ }^{99}$

¿Cuál de los dos se equivoca? Pero de modo independiente a la cuestión de la riqueza apropiable, subsiste el tema del dominio territorial y el control del comercio. El propio Alós cree necesario "pacificar" la región aunque reconoce lo inoportuno de navegar el Bermejo por la falta de fondos para mantener los puertos y los presidios. A cambio de ello habría que instalar dos pueblos de españoles, uno en Remolinos, a treinta leguas de Villa Rica, para conectar con Salta, Jujuy y Tarija, y otro a sesenta o setenta leguas sobre la costa del Bermejo, desde donde se trazaría un camino de carretas.

Este plan apunta al intercambio de bienes más que a una dominación efectiva, política y militar, sobre el Chaco. Los dos pueblos inducirían a los indios a comerciar y las posibilidades de guerra se reducirían al mínimo. Alós termina diciendo que

"nada más civiliza a los indios que el trato recíproco, dándoles en cambio de sus manufacturas nuestras producciones." 100

Este comercio inducido, sin coerción alguna, permitiría extraer las riquezas del Chaco, fueran cuales fueran. También utilizarlo co-

98 Azara, Félix de: Informes sobre varios..., págs. 426-432.

99 García de Solalinde, Antonio: Proyecto de colonización del Chaco, en Colección De Angelis, Buenos Aires, 1836, págs. 439-444.

100 Alós, Joaquín de: Informe al ministro de Gracia y Justicia Eugenio de Llaguno, sobre el poblamiento del Chaco, en Exploración del Gran Chaco. "Revista Paraguaya". Asunción, 1899, págs. 6-8. 
mo vía de comunicación entre el mercado litoral y los andinos ahora separados por un profundo abismo bélico; y por fin terminaría con las guerras y las invasiones depredatorias. Quizá reduciría los gastos militares y eclesiásticos y progresivamente todo el sistema misional-militar sería reemplazado por transacciones libres. Pero otro resultado sería, por supuesto, excluir definitivamente a los pueblos chaqueños del trabajo en las haciendas.

¿Cómo subsistirían esos poblados inductores del comercio interétnico? Habrá que sedentarizar algunos indios aunque ya nadie crea que eso siga siendo posible. El mineral de platina y las moreras producirían ingresos, pero nadie sabe si esas cosas existen allí realmente... la miel sola, allá sí abundante, no podría mantener una economía normal, obligando a todos al auxilio fiscal, por momentos inhallable.

Del Diario de Onofre Xara, enviado por Alós para precisar estas cuestiones en el fuerte del Río del Valle, se obtiene la misma conclusión: abundancia relativa de madera, algunas salinas, pasturas de tanto en tanto, pero ningún otro recurso que asegure el esfuerzo, además de la gravosa pensión de repartir obligadamente animales de modo permanente para sellar la alianza con el indio. ${ }^{101}$

La indefinición de estos planes y la aparente apatía de las autoridades por la región, posiblemente por la certidumbre de que no había más remedio que derrotar al indio y de la incapacidad militar de hacerlo, convertirá al Chaco en un enorme hueco hasta fines del XIX, cuando en otras circunstancias históricas se reitere el plan - exclusivamente militar- de dominación, esta vez de modo moderno y efectivo, es decir, sin contemplaciones de ninguna clase.

Pero la indefinición queda sin resolver y en los últimos años del período virreinal sigue oyéndose el sonsonete de la conquista, de la evangelización. Los proyectos ilustrados de abandonar esos métodos arcaicos y adoptar el intercambio comercial tampoco tienen éxito lucido; cuando se hace mención de algunas hostilidades entre mocovíes y abipones en el Chaco sudoriental, se cree que

101 Xara, Onofre: Diario de Navegación del Bermejo. Ibídem, págs. 39-48. 
"con un puñado de milicianos se hará posible transitar con seguridad los caminos a Santiago, Córdoba y Paraguay". ${ }^{102}$

Necesidad de pacificación, falta de fondos y de proyectos plausibles, evidencia de una derrota colonial. Pero también la angustia sempiterna por resolver las relaciones con tantas tribus distintas, pueblos cuyas miserias materiales se conocen bien, tanto como los métodos de guerra que ellos emplean para resolverlas con eficacia. $\mathrm{Si}$ ninguno de los proyectos se lleva a cabo con éxito, los indios volverán tarde o temprano - todo el mundo lo sabe - a robar ganados en las haciendas españolas.

102 AGN, Justicia, IX, 31-3-5. 